\title{
BILATERAL SYMMETRICAL TENOSYNOVITIS UNIQUE PRESENTATION OF TUBERCULOSIS.
}

Varunjikar. M. D ${ }^{1}$, Mrs Varunjikar A. M², Mrs S. C. Joshi³, C. R. Joshi

1. Associate Professor, Department of Orthopedics, Vikhe Patil Hospital \& Medical College Ahmednagar,
Maharashtra.
2. Consultant Anaesthesiologist, Department of Anaesthesiology, Aryangla Medical College, Satara.
3. Consultant Anaesthesiologist, Department of Anaesthesiology, SR - MGM Hospital, Parel, Mumbai.
4. Consulting Radiologist, Department of Radiology, MGM Hospital, Parel, Mumbai.

\section{CORRESPONDING AUTHOR:}

Dr Varunjikar,

Tathastu 54 Deshmukh Colony, Camp,

Satara- 415001.

Email-varunhsp@yahoo.co.in

\section{HOW TO CITE THIS ARTICLE:}

Varunjikar. M. D, Mrs Varunjikar A.M, Mrs S C Joshi, C. R. Joshi. "Bilateral Symmetrical Tenosynovitis Unique presentation of Tuberculosis". Journal of Evolution of Medical and Dental Sciences 2013; Vol2, Issue 23, June 10; Page: 4218-4222.

ABSTRACT: Bilateral, symmetrical tubercular synovitis is unique entity. We are reporting this unusual case.

INTRODUCTION: Tuberculosis (TB) is still endemic in many developed countries

Involvement of the hand and wrist at presentation is extremely rare, and the diagnosis is often missed

Extrapulmonary tuberculosis involvement of the musculoskeletal system is uncommon, accounting for only $10 \%$ of tuberculosis (TB) cases.

Bone and joint tuberculosis is next to pulmonary affection in tuberculosis. Spine, hip and knee are common joints affected in that chronological order. Double or multiple lesions in bone or joint is uncommon except in spine. Synovitis of tendon is still rarely affected due to tuberculosis. Bilateral synovitis and arthritis is rare entity except in rheumatoid arthritis, and rather rarest in kochs.

We are reporting a case of bilateral, symmetrical tuberculous synovitis.

We were unable to trace such type of presentation of bilateral symmetrical, tuberculous synovitis in literature.

Tuberculous tenosynovitis was first described by Acrel in 1777. Rice bodies occurring in joints affected by tuberculosis were first described in 1895 by Reise. Rice bodies will be diagnosed on plain radiographs when mineralization occurs. More than $50 \%$ of cases recur within 1 year of treatment. The currently recommended 6-month course is often adequate with extensive curettage lavage and synovectomy should be performed. Surgery is essential, but the extent of surgical 
debridement is still debatable. The surgeon has to be aware of the significance of loose bodies when performing routine excision of innocuous looking wrist ganglia.

32 year old male, reported in OPD with complaints of swelling and vague discomfort in both wrists and forearm since 3 month. Swelling, pain and discomfort was gradually increased over the duration of 3 month.

Examination of left forearm and wrist revealed a boggy swelling about $4 \times 3 \mathrm{~cm}$ predominantly on volar aspect, soft, mildly tender, fluctuant, mobile along vertical axis of tendons, trans-illumination absent.

Swelling on right side revealed, $10 \times 6 \mathrm{~cm}$ predominantly on dorsum of forearm, soft, fluctuant, mobile along one axis, non-trans-illuminant. Both swellings were non-pulsatile.

Movements of wrist and forearm were not affected except some weakness in grip in both hands. No neurovascular deficit found.

Past history revealed treatment failure case of pulmonary kochs on irregular treatment (? drop out case). Patient was also chronic alcoholic.

Provisionally diagnosed as B/L tenosynovitis was done.

Important findings in lab investigations were $\mathrm{Hb} 9.5$, CRP positive, ESR 70.

USG s/o soft tissue lesion -most likely giant cell tumor with differential diagnosis of desmoids, hamartoma \& organised Ganglion.

$\mathrm{X}$-ray showed mild porosis with normal wrist joint

After obtaining informed consent, Patient underwent excision biopsy of right sided swelling under tourniquet \& tissue was send for histopathology. Cock-up splint was given for three weeks followed by physiotherapy

Report came out as TUBERCULAR tenosynovitis. Patient was immediately started on CAT 2 and subsequently underwent excision of swelling of the left side after 3 weeks. Histopathology report for other side was also tubercular synovitis.

Patient was followed up at 3 months, 6 months and 1 year and showed good improvement. Patient was assessed clinically, radiologically, and laboratory parameters and showed satisfactory improvement

DISCUSSION: Tuberculous tenosynovitis was first described by Acrel in 1777 [1]. Rice bodies occurring in joints affected by tuberculosis were first described in 1895 by Reise [2]. Rice bodies are a common finding in many rheumatic diseases such as rheumatoid arthritis, systemic lupus erythematosus, seronegative arthritis, nonspecific arthritis, tuberculosis, atypical mycobacterial infections, and osteoarthritic joints (Figure 2) [3]. The sheath of the tendons of the wrist and hand has been reported as a site for rice body formation (Figure 1). Rice bodies will be diagnosed on plain radiographs when mineralization occurs [4]. MRI may show thickening of the synovial membrane with increased vascularization, fluid within the tendon sheath, reactive inflammation around the tendon, or swelling of the tendon [5]. Tendon is replaced by vascular granulation tissue. Sheath is obliterated by fibrous tissue, fluid is confined within the sheath, and rice bodies form due to caseation, and Tendon may consist of only a few strands of tissue and may rupture spontaneously [1]. More than $50 \%$ of cases recur within 1 year of treatment [6]. The currently recommended 6-month course is often adequate with Extensive curettage, lavage and synovectomy 
should be performed. Surgery is essential, but the extent of surgical debridement is still debatable [7].

CONCLUSION: Bilateral symmetrical Tuberculous tenosynovitis of is quite rare and treatment with excision of lesion and antituberculous chemotherapy will minimize recurrence of disease.

The surgeon has to be aware of the significance of loose bodies when performing routine excision of innocuous looking wrist ganglia.

\section{REFERENCES:}

1. S. Aboudola, A. Sienko, R. Carey, and S. Johnson, "Tuberculous tenosynovitis," Human Pathology, vol. 35, no. 8, pp. 1044-1046, 2004.

2. H. Reise, "Die Reiskorpschen in tuberculserkrankensynovalsacken," Deutsche Zeitschrift für Chirurgie, vol. 42, p. 1, 1895 (German).

3. C. L. F. Chau, J. F. Griffith, P. T. Chan, T. H. Lui, K. S. Yu, and W. K. Ngai, "Rice-body formation in atypical mycobacterial tenosynovitis and bursitis: findings on sonography and MR imaging," American Journal of Roentgenology, vol. 180, no. 5, pp. 1455-1459, 2003. View at Scopus

4. J. F. Griffith, W. C. G. Peh, N. S. Evans, L. A. Smallman, R. W. S. Wong, and A. M. C. Thomas, "Multiple rice body formation in chronic subacromial/sub deltoid bursitis: MR appearances,"Brain and Language, vol. 51, no. 7, pp. 511-514, 1996. View at Scopus

5. K. L. Hoffman, A. G. Bergman, D. K. Hoffman, and D. P. Harris, "Tuberculous tenosynovitis of the flexor tendons of the wrist: MR imaging with pathologic correlation," Skeletal Radiology, vol. 25, no. 2, pp. 186-188, 1996. View at Publisher -View at Google Scholar · View at Scopus

6. G. Garrido, J. J. Gomez-Reino, P. Fernández-Dapica, E. Palenque, and S. Prieto, "A review of peripheral tuberculous arthritis," Seminars in Arthritis and Rheumatism, vol. 18, no. 2, pp. 142-149, 1988. View at Scopus

7. L. H. Pimm and W. Waugh, "Tuberculous tenosynovitis," The Journal of Bone and Joint Surgery, vol. 39, no. 1, pp. 91-101, 1957. View at Scopus

\section{Pictures showing swelling of teno synovitis of fore arm \& wrist}

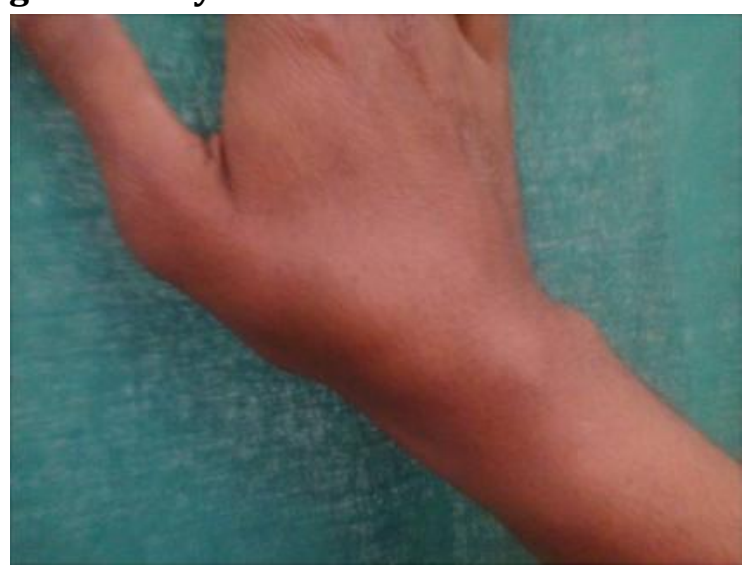




\section{CASE REPORT}

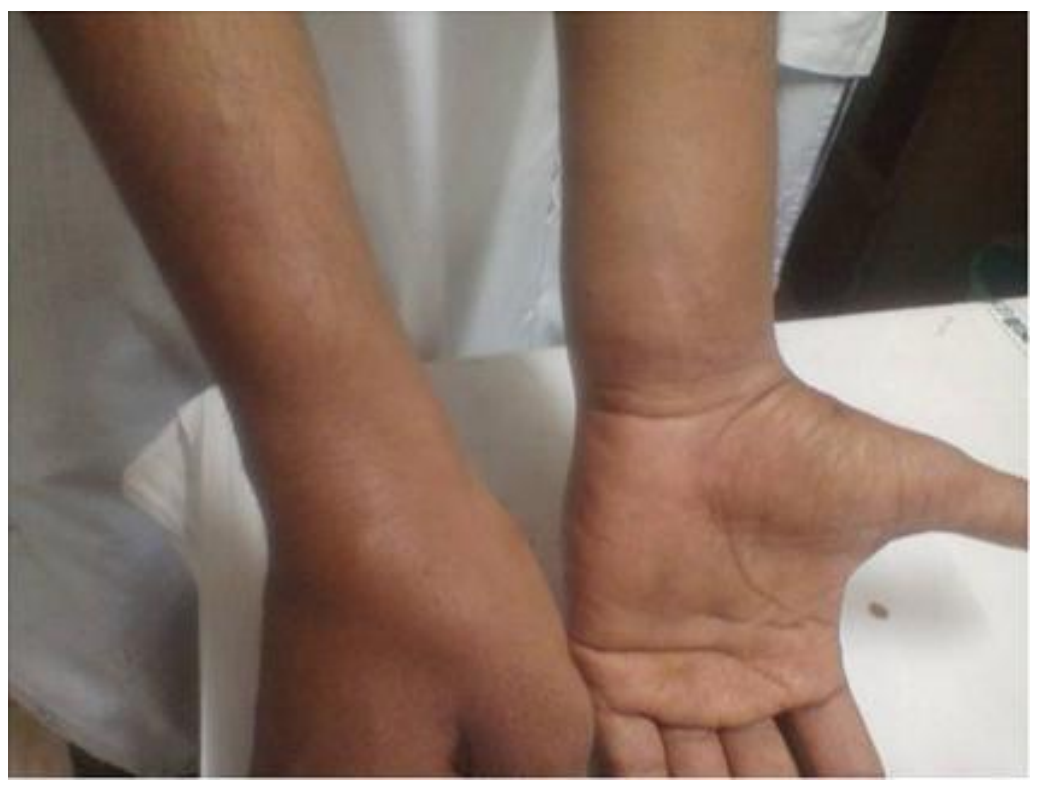

Clinical picture of bilateral tenosynovitis of fore arms

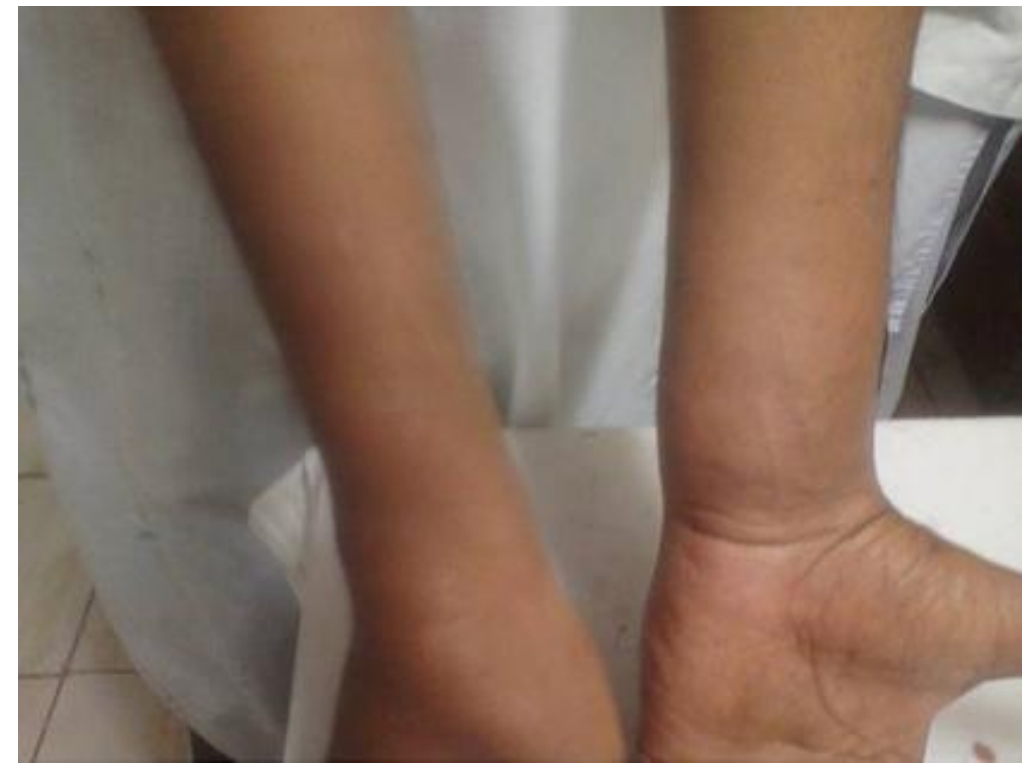

Clinical picture of bilateral tenosynovitis of fore arms 


\section{CASE REPORT}

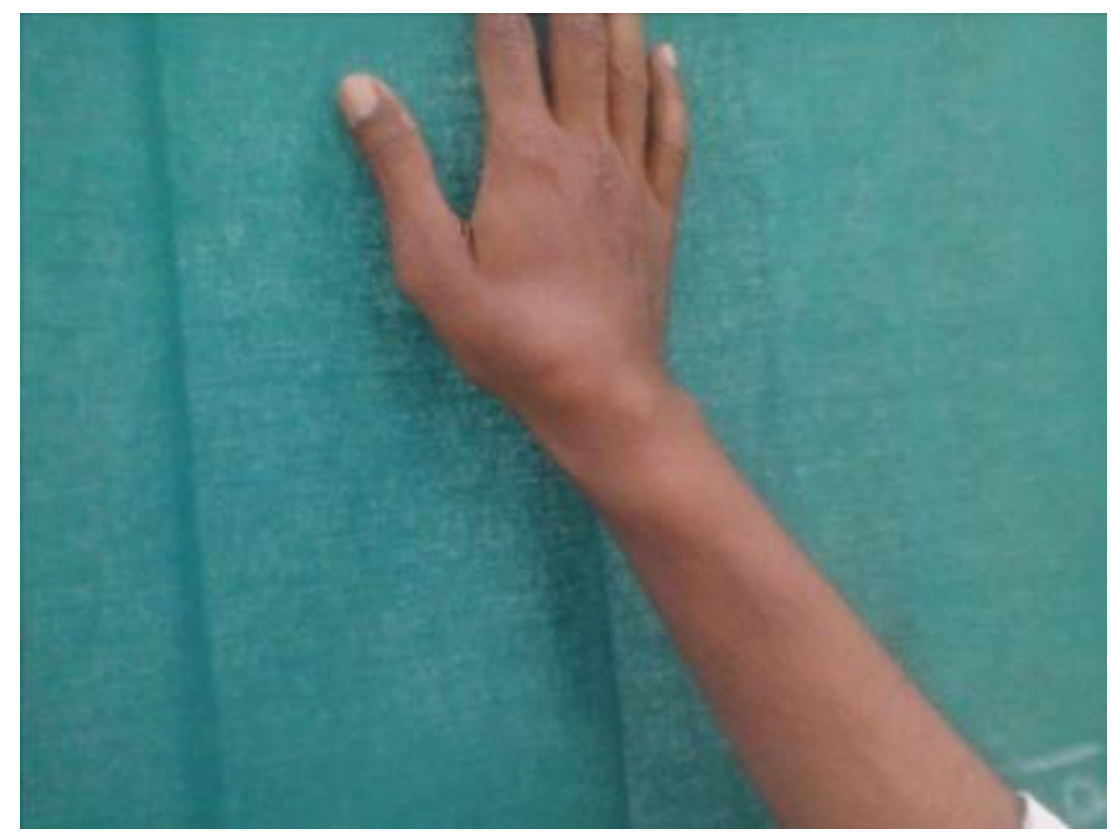

Clinical picture of tenosynovitis of forearms

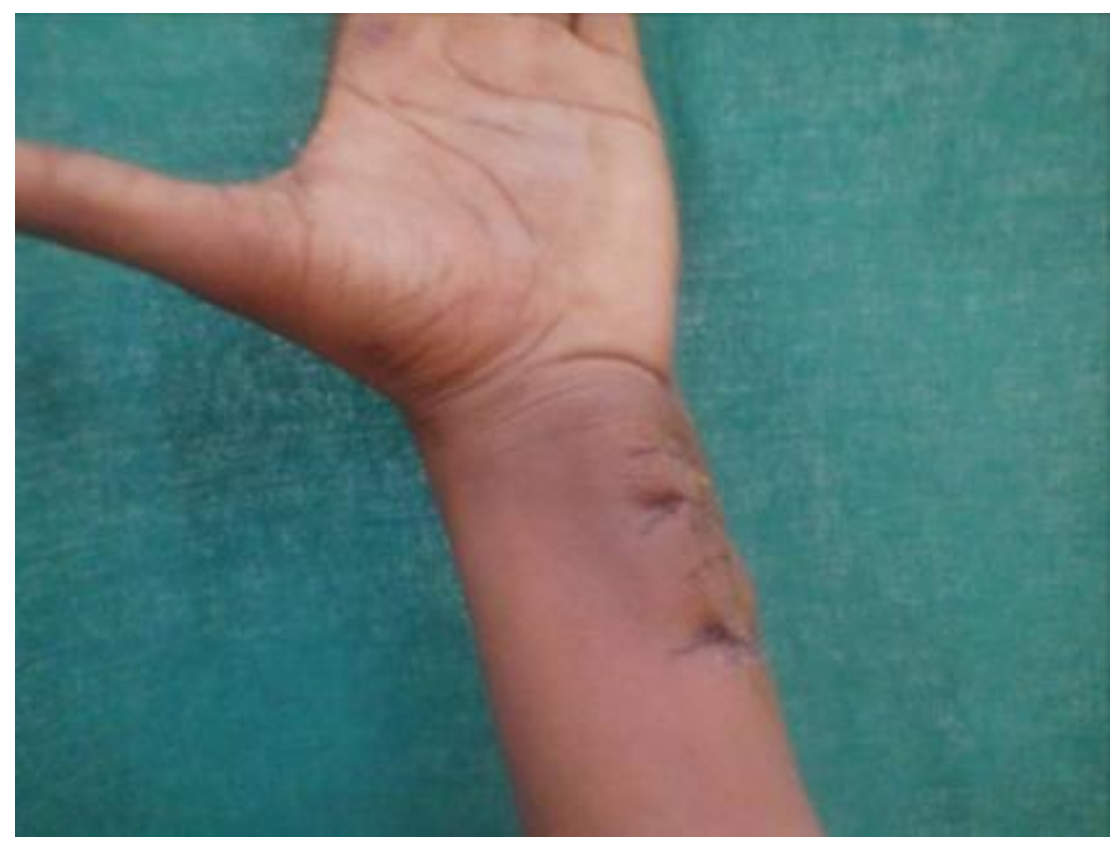

Post Operative clinical photograph . 